Disponível em

http://www.anpad.org.br/rac

RAC, Curitiba, v. 15, n. 1, art. 5, pp. 84-102, Jan./Fev. 2011

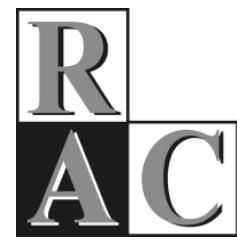

\title{
Repensando Redes Estratégicas
}

\author{
Rethinking Strategic Networks
}

Alexandre Faria *

E-mail: afaria@fgv.br

Fundação Getúlio Vargas - EBAPE/FGV

Rio de Janeiro, RJ, Brasil.

* Endereço: Praia de Botafogo, 190 sala 524, Rio de Janeiro/RJ, 22250-900.

Copyright (C) 2011 RAC. Todos os direitos, até mesmo de tradução, são reservados. É permitido citar parte de artigos sem autorização prévia, desde que seja identificada a fonte. 


\title{
Resumo
}

A disputa política com a área de estudos organizacionais (EO) pela liderança em pesquisa e ensino em administração iniciada nos anos 1960 nos Estados Unidos e a proliferação de escolas de pensamento nos anos 1980 resultaram em questionamentos acerca da relevância da área de estratégia. A globalização neoliberal e seus discursos impulsionaram a construção da relevância da área por meio de crescente especialização e internacionalização; mas questões de poder e política continuam sendo desprezadas pela literatura dominante. Este quadro ajuda a explicar o subdesenvolvimento de pesquisa em redes estratégicas, o problema de relevância das escolas de negócios no mundo anglo-americano, e a resistência de pesquisadores no Brasil e outros países à literatura dominante. A análise mostra que pesquisas em redes estratégicas em economias emergentes devem contemplar questões de poder e política, em perspectiva crítica que desafia assimetrias acentuadas pelo avanço do neoliberalismo, para produzir conhecimento relevante para estrategistas de empresas e do governo e para a sociedade. No Brasil pesquisadores das áreas de estratégia e de EO devem valorizar e reforçar a proximidade entre essas áreas e promover desenvolvimentos interdisciplinares com áreas como geografia, sociologia global e relações internacionais, e em especial com a literatura de redes baseada em economia política internacional.

Palavras-chave: redes estratégicas; economias emergentes; gestão estratégica; realismo crítico; análise histórica.

\begin{abstract}
The political dispute with the field of organization studies (OS) for leadership in research and education in business administration in the US and the proliferation of schools of thought in the 1980s resulted in serious questioning of the relevance of the field of strategy. Neoliberal globalization and its discourses pushed strategists of big corporations and academics to build the relevance of the area through increasing specialization and internationalization, but the dominant literature still ignores power and political issues and downplays government organizations. This helps explain the underdevelopment of research in strategic networks, the translation gap faced by business schools in the Anglo-American world, and the resistance in Brazil and other countries to the dominant literature. Analysis shows that research in strategic networks in emerging economies should make visible power and political issues, particularly from a critical perspective on asymmetries enhanced by the advance of neoliberalism, and produce knowledge that is relevant to strategists from both business firms and government and also society at large. In Brazil, researchers from strategy and OS should value and reinforce the proximity of these fields, and foster interdisciplinary developments with geography, global sociology and international relations and in particular with the literature in networks based on international political economy.
\end{abstract}

Key words: strategic networks; emerging economies; strategic management; critical realism; historical analysis. 


\section{Introdução}

A disputa política com a área de estudos organizacionais (EO) pela liderança em pesquisa e ensino em administração, iniciada nos anos 1960s nos Estados Unidos (EUA), e a correspondente proliferação de escolas de pensamento nos anos 1980 levaram a área de estratégia (chamada de strategic management nos EUA) a um quadro de confusão e descrédito. A relevância da área e sua autoridade foram desafiadas até mesmo por áreas funcionais, tais como gerência de operações e marketing, no final daquela década. A partir do início dos anos 1990, a globalização e seus discursos recolocaram a estratégia no centro das atenções. Um novo cenário de supercompetição, fronteiras mal definidas, e crescente complexidade (Lowendahl \& Revang, 1998), cenário gerado pelo extraordinário avanço da versão neoliberal da globalização - que prescreve a desregulamentação de mercados, liberalização do comércio, e privatização de organizações governamentais e é sustentada por discursos e imagens fomentadas e disseminadas por elites de poder que preconizavam as virtudes de mercados desregulamentados e integrados globalmente (Steger, 2003) lançou estrategistas de grandes corporações e pesquisadores nos EUA à construção da relevância da área. Em paralelo, cresceram as críticas à irrelevância de EO (Walsh, Meyer, \& Schoonhoven, 2006), as críticas de autores de EO à hegemonia anglo-americana (e.g., Vergara, 2001) e, correspondentemente, a especialização acadêmica em estratégia e o distanciamento entre estratégia e EO nos EUA.

Um dos principais desafios passou a ser a dimensão invisível, descrita por um renomado defensor da hiperglobalização neoliberal, com o auxílio da imagem do iceberg, como a parte mais significante da estratégia e que costuma ser intencionalmente tornada não visível.

The visible clashing between companies in the marketplace - what managers frequently think of as strategy - is but a small fragment of the strategic whole. Like an iceberg, most of strategy is submerged, hidden out of sight. ... The visible part can foam and froth with head-to-head competition. But most of it is intentionally invisible - beneath the surface where value gets created, where competition gets avoided. (Ohmae, 1988, p. 150).

Pesquisadores de estratégia (i.e., strategic management, como a área é denominada nos EUA) desafiaram lógicas tradicionais de causa e efeito (Gaddis, 1997), reconheceram algumas dimensões invisíveis da estratégia (Godfrey \& Hill, 1995; Lowendahl \& Revang, 1998), por meio de novas escolas e modelos influenciados pelos fundamentos do neoliberalismo, e privilegiaram a especialização acadêmica e a crescente internacionalização com base na ideia, ressaltada pela literatura de relações internacionais, de que com o fim da Guerra Fria os "Estados Unidos passaram a dominar o mundo como nenhum outro Estado havia feito" (Ikenberry, 2004, p. 144). Porém a literatura dominante continua ignorando questões de poder e política, as quais continuam sendo ressaltadas pela área de EO, apesar de restrições institucionais crescentes (Courpasson, Arellano-Gault, Brown, \& Lounsburry, 2008) e privilegiadas por outras áreas do conhecimento, tais como geografia, sociologia global, relações internacionais e notadamente economia política internacional (devido à supressão delas no mundo acadêmico, em face do avanço da globalização neoliberal). Além disso, a literatura dominante continua desprezando as organizações governamentais e seus estrategistas, que são especialmente importantes para economias emergentes, para outros tipos de capitalismo (Albert, 1992); finalmente para a "nova era do pós-neoliberalismo" (Altvater, 2009, p. 12), inaugurada com a grande crise dos mercados financeiros em meados de 2008. Em resumo, a relevância da literatura dominante de estratégia e ainda mais questionável em perspectiva internacional do que nos EUA.

A maioria dessas críticas à área de estratégia vem sendo feita por pesquisadores de fora dos EUA e vinculados à área de EO (e.g., no exterior, Carter, Clegg, \& Kornberger, 2008; Clegg, Carter, \& Kornberger, 2004; Knights \& Morgan, 1991; Whittington, 2004; e no Brasil, Bertero, Vasconcelos, \& Binder, 2003; Bignetti, 2008; Machado-da-Silva, 2004; Saraiva \& Carrieri, 2009). O argumento a seguir traduz o quadro de descontentamento de acadêmicos vinculados a EO com os desenvolvimentos produzidos pela área de estratégia e sua trajetória de crescente especialização e internacionalização: "chegamos a um quadro em que a maioria dos modelos de pensamento estratégico, se não todos, 
alcançou um nível de representação que é desconectada da realidade ... elas são incapazes de lidar com as supostas realidades que dizem representar” (Grandy \& Mills, 2004, p. 1167).

Estas críticas e as críticas à hegemonia dos EUA no campo da administração feitas em diferentes países (e.g., Ibarra-Colado, 2006; Westwood \& Jack, 2008) e também no Brasil (e.g., Vergara, 2001) vêm sendo ignoradas pela literatura dominante de estratégia. Esse quadro é preocupante porque a área de estratégia protagoniza o problema de translation gap - i.e., o descasamento entre interesses e práticas de acadêmicos e estrategistas - enfrentado por escolas de negócios no mundo anglo-americano (Ghoshal, 2005; Khurana \& Marquis, 2006); e seus autores afirmam que conhecimento acadêmico em administração tem de se vincular aos interesses e práticas dos estrategistas das grandes empresas para atender aos desafios da globalização.

O desprezo por questões de poder e política (e a correspondente ênfase em ética e responsabilidade social corporativa) e o papel proeminente da área de estratégia em ensino e pesquisa no mundo anglo-americano têm importantes implicações para economias emergentes. Uma primeira questão é que acadêmicos e instituições dos EUA, em consonância com a trajetória de crescente especialização e internacionalização, passaram a produzir conhecimento focado nas grandes economias emergentes sem considerar as críticas quanto à omissão de questões de poder e política (e.g., Hoskisson, Eden, Lau, \& Wright, 2000). Uma segunda questão é que as redes estratégicas em economias emergentes (que se tornaram um foco especial de atenção para esses pesquisadores) são tratados numa perspectiva que reforça o domínio anglo-americano (e.g., Peng \& Pleggenkuhle-Miles, 2009) e, obviamente, restringe o desenvolvimento internacional da área de estratégia. A imagem do iceberg ajuda a traduzir esse desafiante quadro: a literatura dominante de estratégia, cada vez mais presente no mundo e em especial em economias emergentes, mantém invisível não somente as questões de poder e de política, que são importantes para estrategistas de organizações privadas e governamentais, especialmente em economias emergentes, mas também as que ajudam a reforçar e explicar a hegemonia anglo-americana.

O âmbito de redes estratégicas foi fortemente afetado por este quadro de omissão (ver, e.g., Welch \& Wilkinson, 2004), que é particularmente desafiante para as grandes economias emergentes tais como China, Índia, Brasil e Rússia. Estes países seguem outros tipos de capitalismo - em especial o capitalismo de rede (Boisot \& Child, 1996; Koniordos, 2005) - e em conjunto desafiam a tese de que todos os países convergirão para o capitalismo neoliberal (ver Albert, 1992; Arbix, Comin, Zilbovicius, \& Abramovay, 2002). As grandes economias emergentes representam um desafio à hegemonia dos EUA e isso ajuda a explicar os crescentes investimentos feitos nos EUA em pesquisa em ensino em estratégia focado nestes países (Ricart, Enright, Ghemawat, Hart, \& Khanna, 2004).

Diferentemente do que prescreve o capitalismo neoliberal e a literatura dominante de estratégia, as redes estratégicas em economias emergentes costumam envolver empresas privadas e organizações governamentais nacionais e internacionais. Os crescentes volumes de investimentos diretos dos EUA em economias emergentes nos últimos anos, especialmente na China, vêm sendo efetuados por redes estratégicas que envolvem governo federal e grandes corporações, contando com o poderio militar daquele país (Harvey, 2007). Questões de poder e política internacional no âmbito de redes estratégicas têm sido ressaltadas pela literatura baseada em economia política internacional (e.g. Arbix et al. 2002; Benson, 1994; Gereffi, Humphrey, \& Sturgeon, 2005; Haley \& Tan, 1999; Henderson, Dicken, Hess, Coe, \& Yeung, 2002; Humphrey, 2003; Lecraw, 1984; Yeung, 2005). Entretanto os pesquisadores e instituições dedicadas a construir conhecimento em estratégia focado em economias emergentes (e.g., Peng, Wang, \& Jiang, 2008) não reconhecem esta literatura.

A superação deste quadro (pela literatura dominante) não é fácil, principalmente devido ao poder de duas imagens relacionadas ao capitalismo liberal de mercado nos EUA. A imagem da firma como entidade autônoma em busca de vantagem competitiva, apoiada pela hegemonia do campo da economia em estratégia nos EUA (Rumelt, Schendel, \& Teece, 1991), ajuda a explicar o subdesenvolvimento da pesquisa em redes estratégicas. Por sua vez, a imagem da mão visível (Chandler, 1977, 1984), que afirma que gerentes controlam as grandes corporações e que estas são a força-motriz da economia nacional, inibe o reconhecimento de redes que envolvem governos e 
empresas. Estas poderosas imagens afetam as práticas dos acadêmicos da área quanto à literatura dominante dentro e fora dos EUA.

O principal objetivo deste artigo é mostrar que pesquisas em redes estratégicas no Brasil devem reconhecer questões de poder e política (que ficaram na parte invisível do iceberg), para viabilizar a produção de conhecimento relevante para estrategistas de organizações privadas e governamentais em economias emergentes. Na próxima seção é descrito o problema de relevância em estratégia e o reflexo deste problema no âmbito das redes. Na terceira é apresentada uma abordagem crítica, baseada na ontologia de realismo crítico e contando com o auxílio da imagem do iceberg, que objetiva tornar visíveis questões de poder e política nos âmbitos das redes estratégicas e do conhecimento acadêmico em estratégia. Na quarta, com base na abordagem crítica proposta e na literatura de redes baseada em economia política internacional, é analisada a influência do setor automotivo na literatura em redes estratégicas nos anos 1990. Na última seção são apresentadas as implicações da abordagem proposta para estrategistas e acadêmicos no Brasil.

\section{O Problema de Relevância em Estratégia}

Até o início dos anos 1980 a área de estratégia era modesta nos EUA. A disputa com a área de EO pela liderança na academia de administração era caracterizada por um quadro de grande assimetria; diferentemente de EO, não havia bons periódicos nem acadêmicos com carreira estabelecida em estratégia na época - com exceção dos acadêmicos em business policy de Harvard. Nos anos 1980s esse quadro foi fortemente alterado a partir do lançamento do Strategic Management Journal e da subsequente proliferação de escolas de pensamento.

A área de strategic management, que se tornou denominação dominante nos EUA e no exterior a partir do lançamento do Strategic Management Journal em 1980, tinha como objetivo central publicar conhecimento acadêmico que fosse relevante para estrategistas. A área contemplaria não somente grandes corporações, mas também outros tipos de organização; não somente gerentes de topo, mas também gerentes dos outros níveis; não somente o plano estratégico, mas também as mudanças dentro da empresa (Schendel, Ansoff, \& Channon, 1980). Em pouco tempo a área incorporou diversas bagagens teóricas, vindas do campo da economia, tais como organização industrial, teoria dos jogos, economia de custo de transação, teoria da agência, abordagem de recursos, economia evolucionária, capacitações dinâmicas (Hambrick, 2004), mas manteve invisíveis questões de poder e política.

As disputas subsequentes entre defensores de escolas ou igrejas pela primazia na área, com forte influência de grandes empresas de consultoria (Clark, 2004; Cummings \& Wilson, 2003), ajudam a explicar a atual crise de relevância da área e o problema de relevância enfrentado atualmente pelas escolas de negócios. Os equívocos resultantes e a crescente importância das corporações e seus estrategistas, devido ao avanço do neoliberalismo, ajudam a explicar a grande preocupação de autores europeus com as consequências da área para indivíduos e sociedade (Hambrick, 2004; Knights \& Morgan, 1991; Whittington et al., 2003), e também as críticas à hegemonia dos EUA no campo da administração (Clegg et al., 2004; Ibarra-Colado, 2006).

Sob a perspectiva de economias emergentes, esse quadro apresenta três grandes problemas: (a) o domínio do campo da economia (Rumelt et al., 1991; Seth \& Thomas, 1994), em detrimento de outros campos do conhecimento que contemplam questões de poder e política; (b) a predominância da abordagem positivista, em detrimento de outras abordagens epistemológicas, que lidam melhor com questões invisíveis de poder e política (Snow \& Thomas, 1994); e (c) a hegemonia dos EUA (Phelan, Ferreira, \& Salvador, 2002) e a exportação de forma acrítica e assimétrica de conhecimento para outros países e regiões (Haley \& Tan, 1999) nos quais as questões de poder e política são cruciais para organizações e estrategistas. 
As concepções ou imagens da realidade estabelecidas pela literatura dominante ficaram mais importantes do que a própria realidade. Os critérios estabelecidos pela área forçaram e incentivaram pesquisadores (nos EUA) a produzir pesquisa que reproduzisse teorias que fossem tidas como importantes pela própria área. Isso tanto ajudou a elevar a reputação da área junto a acadêmicos e suas instituições quanto reduziu a relevância do conhecimento para estrategistas e organizações.

\section{O problema da relevância no âmbito de redes}

Um dos principais problemas advindos da proliferação de escolas em estratégia e da trajetória de crescente especialização e internacionalização nos EUA é que pesquisadores de determinada escola não reconhecem ou confrontam as outras escolas (Combe, 1999; Hambrick, 2004). Pesquisadores têm dificuldades para contemplar as diferenças em um mundo que insiste em desafiar a tese neoliberal da convergência (Schelhase, 2008). Além disso, podemos citar a histórica rejeição da crítica e a virtual ausência de questionamentos ontológicos na área (Pettigrew, Thomas, \& Whittington, 2002).

Nos anos 1990, quando a imagem da firma autônoma foi desafiada nos EUA e as redes foram timidamente, em relação ao que ocorria na literatura européia, reconhecidas pela literatura daquele país, a pesquisa neste âmbito reproduziu o principal duelo de escolas da área de estratégia: questões humanas versus questões econômicas (Mintzberg \& Quinn, 2001). Esse duelo restrit(iv)o (Tsoukas, 1994a; Whittington, 2004) mantém invisíveis questões de poder e política e isso ajuda a explicar o quadro de subdesenvolvimento da pesquisa em redes.

Os defensores da corrente econômica - que compõem a maioria e seguem o positivismo epistemológico - representam redes como sistemas objetivos que geram vantagens competitivas para seus membros por meio do planejamento (e.g. Lamming, 1993; Lorenzoni \& Baden-Fuller, 1995). Os defensores da corrente humana - que compõem a minoria e seguem a abordagem interpretivista representam redes como sistemas subjetivos, de fronteiras mal definidas, e complexas demais para serem controladas por um ator central (e.g. Axelsson \& Easton, 1992; Mattsson \& Johanson, 2006). Os primeiros, notadamente nos EUA, preferem a imagem de redes como hierarquias; os segundos, em alguns países da Europa, a imagem de redes como mercados.

Pesquisadores não costumam confrontar essas imagens ou correntes em seus trabalhos nem questionar se acadêmicos, ao invés dos estrategistas, estão em melhor posição para definir a realidade. Como resultado, estrategistas têm que (re)construir imagens dos acadêmicos em suas práticas para enxergarem o que está além da parte visível do iceberg (Ohmae, 1988) ou, no fluir do tempo, disseminar tais imagens ou correntes para que outros não vejam a dimensão mais significante da estratégia. Especialmente por causa do poder relativo da estratégia no campo da administração (Alvesson, Willmott, \& Levy, 2003), estrategistas também podem restringir ou bloquear a disseminação de imagens, correntes ou escolas que reconheçam questões de poder e política. Em termos mais específicos, estrategistas podem preferir que pesquisas em redes estratégicas não tornem visíveis os relacionamentos e as interações entre grandes corporações e governos.

Esse quadro não é muito surpreendente numa perspectiva geopolítica. Segundo a literatura de relações internacionais, tendo em vista o argumento de que a era da globalização neoliberal representa a primeira vez, na era moderna, em que "o Estado mais poderoso do mundo pode atuar no cenário global sem restrições de outras grandes potências” (Ikenberry, 2004, p. 145). Esse poder vem sendo intencionalmente disfarçado ou tornado invisível, porque "quando é exposto e percebido como dominação inevitavelmente convida a respostas e reações” (Ikenberry, 2004, p. 145). Em outras palavras, estrategistas podem colaborar para o subdesenvolvimento da área de estratégia; isso pode ajudar a explicar tanto as disputas políticas entre estratégia e EO quanto o problema de relevância enfrentado por escolas de negócios no mundo anglo-americano. Isso também pode explicar por que a literatura de estratégia ignora as críticas à hegemonia anglo-americana no campo da administração.

O setor automotivo - em especial nos EUA e no Reino Unido - está fortemente relacionado ao subdesenvolvimento da pesquisa em redes na área de estratégia. A partir do início dos anos 1990, grandes empresas do setor automotivo desafiaram o paradigma da firma autônoma. Curiosamente, este 
paradigma foi reforçado e disseminado pela área de estratégia e pelo setor automotivo dos EUA, em consonância com o modelo americano de negócios baseado nas ideias de free enterprise e free market (Kay, 2004) e com as estratégias de expansão internacional de grandes corporações americanas, e lideraram o processo de construção de redes internacionais de fornecedores. Grandes montadoras também financiaram a produção e a difusão internacional do conhecimento acadêmico que descrevia redes como fontes de vantagem competitiva no mercado global, ao invés de como obstáculo para os fundamentos legais e teóricos do modelo de free enterprise e free market. Reproduzindo o modelo japonês, alguns grandes fornecedores foram transformados em gerentes de redes - também chamados de first-tier suppliers - pelas montadoras. Esses gerentes, muitos deles localizados em economias emergentes, ganharam responsabilidades estratégicas. Aos fornecedores que não foram excluídos das redes, foram atribuídas responsabilidades operacionais.

Segundo esse modelo baseado na imagem de redes como hierarquias e no discurso neoliberal de convergência em um mundo sem fronteiras, a principal função estratégica dos gerentes de redes é cooperar com as montadoras e eliminar conflitos nos níveis inferiores ou operacionais das redes. Se esse modelo não funcionar, a montadora tem o poder de rebaixar o gerente para o nível operacional ou mesmo excluí-lo da rede (Lamming, 1993), o que em grande parte é explicado por assimetrias internacionais que foram acentuadas pelo neoliberalismo (Benko \& Strohmayer, 1997; Harvey, 2007; Sklair, 2002). Pesquisadores europeus que defendem ou preferem a imagem de redes como mercados produziram pesquisas que desafiavam esse tipo dominante de literatura, mas não se preocuparam com questões de assimetria internacional. Eles argumentaram que as redes são pouco gerenciáveis ou controláveis pelas montadoras por causa de questões de embeddedness ou embutimento social, que desafiam a racionalidade imposta por pesquisadores que preferem a imagem de redes como hierarquias.

A partir de meados dos anos 1990, após a instalação das redes internacionais em diversos países e regiões, decresceu o interesse das montadoras pelas redes sob uma perspectiva estratégica. A perspectiva operacional passou a ser dominante e o conhecimento em redes passou a ser protagonizado pela área de gerência de operações no mundo anglo-americano. Questões de poder e de política em redes estratégicas e organizações governamentais eram enfatizadas por pesquisas baseadas na literatura de economia política internacional. Essa literatura sobre redes foi menosprezada pelas montadoras e também pelos pesquisadores das áreas de estratégia e de gerência de operações. Ao invés de reconhecer essa literatura, a área de estratégia nos EUA concluiu que pesquisas no âmbito de redes têm de se basear no conhecimento mainstream de estratégia (Gulati, Nohria, \& Zaheer, 2000a).

Um número especial do Strategic Management Journal (SMJ), publicado em 2000, revelou as muitas dúvidas nos EUA quanto à relevância das redes estratégicas e do conhecimento especializado. Nesse âmbito, a literatura de redes estratégicas foi revista e avaliada como complexa e irrelevante (Gulati et al., 2000b) e concluiu-se que pesquisas neste âmbito têm de se basear nas novas escolas de estratégia - i.e. recursos (Barney, 1991) e capacitações dinâmicas (Teece, Pisano, \& Shuen, 1997). Essa proposta reforça o domínio do campo na economia na área (Carter et al., 2008), e reproduz o lema central para a área de estratégia no país que detém o domínio do mundo no período pós-Guerra Fria, i.e. "maximizar o valor, não a complexidade” (Ghemawat, 2006, p. 77). Essa proposta também ajuda a explicar o problema de relevância, enfrentado por escolas de negócios, e as críticas à hegemonia dos EUA no campo da administração (Clegg et al., 2004; Clegg \& Ross-Smith, 2003; Ibarra-Colado, 2006). Finalmente, e mais preocupante, essa proposta ajuda a explicar os investimentos feitos recentemente por pesquisadores e instituições dos EUA na produção de conhecimento relevante para economias emergentes (e.g., Peng \& Pleggenkuhle-Miles, 2009).

A imagem do iceberg ajuda a descrever esse quadro. Questões cruciais para estrategistas foram tornadas invisíveis pela literatura dominante, devido principalmente ao poder relativo de imagens dominantes nos EUA e a questões invisíveis que afetam a pesquisa e o ensino de estratégia. Consequentemente, as questões de poder e política que interessam a estrategistas de grandes corporações e governos e fazem parte de suas práticas, especialmente (mas não somente) em economias emergentes, permanecem invisíveis. 
Dentre as dimensões invisíveis na literatura dominante de estratégia, que são visíveis para a literatura de redes baseada em economia política internacional, destacam-se as seguintes: (a) o poder político e econômico de corporações transnacionais e multinacionais junto a governos e mercados nacionais (Murtha \& Lenway, 1994; Sklair, 2002); (b) o papel de políticas dos EUA para o desempenho de empresas de setores estratégicos no exterior (Brahm, 1995; Murtha \& Lenway, 1994); e (c) a influência das relações entre países sobre as estratégias e desempenho de grandes corporações e das redes lideradas por essas organizações (Sklair, 2002; Ramamurti, 2001).

Essas questões são fundamentais para estrategistas em economias emergentes e ajudam a explicar por que a retórica da globalização neoliberal tem sido sustentada pelo inigualável poderio militar do mundo anglo-americano em um mundo supostamente sem fronteiras e governado por forças de mercado (Harvey, 2007). As pesquisas baseadas na literatura de economia política internacional têm analisado as implicações das redes assimétricas de produção global, com ênfase no setor automotivo. Essas análises mostram que os centros estratégicos dessas redes se concentram nas economias desenvolvidas e, por sua vez, as periferias operacionais se concentram em economias emergentes ou menos desenvolvidas (ver Dicken, Kelly, Olds, \& Yeung, 2001; Kaplinski, 2004). Essas redes são influenciadas e sustentadas pelas relações assimétricas entre países ou blocos regionais e têm sido importantes também para neutralizar ou mesmo desmantelar as redes estratégicas que envolvem organizações privadas e públicas em economias emergentes (Rodrígues-Pose \& Arbix, 2001).

\section{A Imagem do iceberg e o realismo crítico}

Acadêmicos vinculados aos EO conceberam um total de 13 imagens de estratégia (Cummings \& Wilson, 2003) com o propósito de ajudar a superar o gap entre praticantes e acadêmicos. Eles argumentam que estrategistas e acadêmicos lidam com a realidade de formas distintas. Acadêmicos se dedicam a construir e reforçar escolas de pensamento, o que os torna prisioneiros de determinadas imagens. Estrategistas se dedicam a (re)construir e usar imagens - muitas delas produzidas por acadêmicos - para simplificar a realidade e orientar suas práticas.

Argumenta-se neste artigo que pesquisadores podem usar imagens do mesmo modo que estrategistas para ajudar na construção de uma abordagem crítica de redes estratégicas que permita a construção de conhecimento relevante em economias emergentes. Por meio da imagem do iceberg (ver Figura 1), pesquisadores podem visualizar antecedentes e implicações desse problema e enxergar além da ponta do iceberg, i.e. a pequena parte visível de um problema maior que continua oculto.

Na imagem a seguir, uma fotomontagem do que pode ser um iceberg inteiro. A parte superior é uma imagem real; a submersa é uma imagem invertida de outro iceberg.

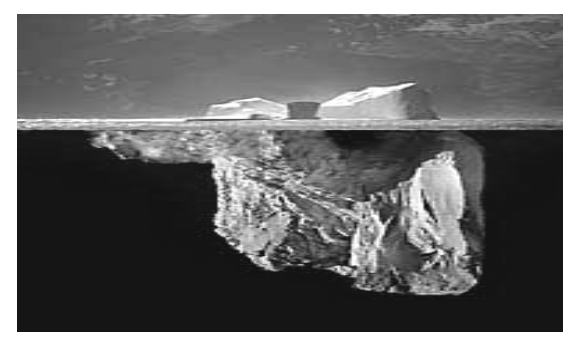

Figura 1. Imagem do Iceberg

Nota. Fonte: Kils, U. (2006, julho). File:Iceberg.jpg. Recuperado de http://commons.wikimedia.org/wiki/Image:Iceberg.jpg

O acidente protagonizado pelo Titanic em 1912 nos ensinou, de forma dramática, que as aparências acerca da realidade são enganosas. A fragilidade das aparências, ilustrada pela imagem do iceberg, ajuda a explicar por que estrategistas preferem usar diversas imagens e de diferentes maneiras, ao invés de preferirem uma imagem específica, para a construção de mapas plausíveis da realidade e testá-los na prática (Cummings \& Wilson, 2003). Questões de poder e política também podem explicar por que estrategistas podem preferir a disseminação de imagens equivocadas. A 
imagem do iceberg é análoga aos princípios do realismo crítico (RC), descrito no Strategic Management Journal como base ontológica importante para a construção da relevância da área (Kwan \& Tsang, 2001), e que, no entanto, permanece inexplorado, devido, entre outras razões, à aversão da área à complexidade, crítica e questionamentos ontológicos.

A imagem do iceberg pode ajudar a traduzir o RC para a área de estratégia e, assim, facilitar o reconhecimento de questões de poder e política em pesquisas futuras. RC argumenta que a realidade existe independentemente, ainda que não completamente, de nossos conhecimentos ou conceitos. Conhecimento é tido como falível e não neutro; por essa razão conhecimento pode também tornar invisível aos atores sociais a realidade e seus mecanismos, estruturas e redes causais (Bhaskar, 1989). Segundo o RC, o pesquisador deve desafiar as aparências e também os conhecimentos estabelecidos sobre a realidade para tentar a descoberta do real.

Mais especificamente, RC desafia a imposição de teorias ou imagens preferidas pelo pesquisador sobre a realidade por meio do positivismo estatístico (Mir \& Watson, 2000). Ainda que alguns constructos na área de estratégia sejam não observáveis (Godfrey \& Hill, 1995), por exemplo, pesquisadores encontram regularidades empíricas referentes a estes contructos não observáveis por meio da aplicação de testes estatísticos. O problema, segundo RC, é que tanto os dados quanto os testes atendem aos preceitos de determinada escola. Isso ajuda a ilustrar a tese de falibilidade do conhecimento científico.

RC também desafia o argumento interpretativista extremo. Uma parcela menor das pesquisas em estratégia se baseia nesta abordagem, a qual pressupõe estratégia como "um processo eminentemente criativo que não pode ser abstraído fora de seu contexto” (Tsoukas, 1994a, p. 776). Essas pesquisas se concentram em descrever, e a partir dessa base também explicar, os significados atribuídos por praticantes. Porém, segundo o RC, as descrições produzidas por informantes (ou empresas) não podem ser tidas como equivalentes à realidade ou neutras. Essa característica é particularmente importante na área de estratégia, em especial se reconhecermos a importância das questões de poder e política.

Isso não quer dizer que as descrições e explicações dos informantes (que nem sempre são os principais praticantes de estratégia em uma grande empresa ou organização governamental) não são importantes para a descoberta da realidade pelo pesquisador. RC ressalta que a realidade é parcialmente conhecida e construída socialmente por informantes e/ou estrategistas (Fleetwood \& Ackroyd, 2004) e que cabe ao pesquisador testar a plausibilidade das descrições e explicações dos atores sociais para descobrir a realidade.

Relatos, significados e respostas dos informantes costumam ser distorcidos pela "lógica dominante” da empresa (Bettis \& Prahalad, 1995, pp. 6-7) ou por escolas ou imagens dominantes em estratégia. Ademais e correspondentemente, informantes costumam omitir ou disfarçar questões de poder e política, quando perguntados sobre questões de estratégia. Um problema adicional e mais preocupante é que, a despeito dos significados e descrições produzidas por informantes, os pressupostos das escolas acabam, muitas vezes, determinando "quais fatores serão selecionados como importantes” pelo pesquisador nas fases de descrição e análise de resultados (Wilson, 1992, p. 24). Como ressaltado pelo RC, ao invés de um espelho da realidade, a verdade em estratégia acaba transformando-se em "uma questão de convenção" (Sayer, 1992, p. 75), não importando que o pesquisador siga o positivismo estatístico ou o intrepretivismo. A precedência das teorias ou imagens estabelecidas pela literatura dominante em relação à realidade garante a supressão do invisível e bloqueia o desenvolvimento de conhecimento relevante.

Segundo o RC, esses problemas são de natureza ontológica ou epistemológica, e não referentes a conceitos ou métodos de pesquisa. Ontologia é a ciência ou o estudo do que existe; refere-se a pressupostos sobre "o que existe, como se parece, quais unidades a compõe e como essas unidades interagem entre si” (Blaikie, 1993, p. 6). Epistemologia é uma teoria ou ciência do conhecimento; refere-se a pressupostos sobre "como o que existe pode ser conhecido ... o que pode ser conhecido, e quais critérios esse conhecimento tem que satisfazer para ser chamado de conhecimento ao invés de 
crença” (Blaikie, 1993, p. 7). RC afirma que a realidade existe e que esta independe, não totalmente, de nosso conhecimento, interpretação ou observação. Ciência é definida então como atividade que visa "a descobrir, por meio de uma mistura de experimentação e razão teórica, as entidades, estruturas, mecanismos (visíveis ou invisíveis) que existem e operam no mundo” (Bhaskar, 1998, p. 322).

A realidade é composta de estruturas, mecanismos e redes causais que se dispõem verticalmente. Estas dimensões produzem a maioria dos eventos e experiências que costumamos observar. Às vezes, essas dimensões se opõem e isso impede a manifestação de eventos e experiências observáveis. Em outras palavras, a não observação de um evento não significa a inexistência de mecanismos, estruturas e redes causais correspondentes. A imagem do iceberg ajuda a ilustrar esse argumento (ver fig. 2). Os mecanismos, estruturas e redes que formam a ponta do iceberg estão presentes abaixo do nível do mar em locais em que não vemos coisa alguma sobre a superfície. Por isso não bastava ao comandante do Titanic desviar da parte visível do iceberg. O descasamento entre invisível e visível ilustra quanto o conhecimento é falível e ajuda a explicar por que a construção e difusão de imagens é importante tanto para superar o problema, quanto, por outro lado, para causar problemas a outros.

O RC afirma que o real, o domínio no nível mais elevado, é formado por redes, agentes, mecanismos e estruturas não necessariamente empíricas, que toma a forma de eventos, isto é, o factual. O domínio do factual inclui não apenas experiências, mas também eventos, que podem ser observados ou não, por não existir alguém para observá-los, ou por serem muito pequenos ou grandes ou muito rápidos ou lentos para serem percebidos (Outhwaite, 1983). Alguns destes eventos se manifestam no nível da experiência - o empírico -, outros não. O empírico é descrito como "um subconjunto do factual, o qual é em si um subconjunto do real” (Bhaskar, 1989, p. 100). Diferentes estruturas e mecanismos podem contra-agir e, assim, produzir 'não eventos' no nível do factual. De forma análoga, eventos podem ocorrer sem que sejam experimentados ou observados (Bhaskar, 1989, p. 16) no nível empírico.

Os sinais da figura 2 (v) indicam os domínios de realidade, em cujos mecanismos, eventos e experiências residem, bem como os domínios envolvidos, para que tais residências e existências sejam possíveis. Experiências, por exemplo, são eventos identificados no domínio do empírico. Estas pressupõem a ocorrência de eventos e ações no domínio do factual, independentemente de nossa observação deles no nível do empírico. Eventos pressupõem a existência de mecanismos e estruturas no domínio do real que são responsáveis pela geração desses eventos e de outros que, eventualmente, não são identificados (ver Tsoukas, 1994b, p. 291). Assim como o capitão do Titanic, ou os estrategistas que manipulam imagens para construir e testar representações mais plausíveis da realidade, o pesquisador não se deve concentrar na dimensão visível. A descoberta da realidade requer que o pesquisador se mova desde o fluxo de eventos mais visíveis/observáveis para os "mecanismos causais, estruturas sociais, poderes e relações que governam tais eventos” (Ackroyd \& Fleetwood, 2000, p. 13).

\begin{tabular}{|lcccc|}
\hline & Real & Factual & Empírico \\
\hline Experiências/percepções & $\mathrm{v}$ & $\mathrm{v}$ & $\mathrm{v}$ \\
$\begin{array}{l}\text { Eventos/ações } \\
\begin{array}{l}\text { Mecanismos/estruturas } \\
\text { atores/ redes de poder }\end{array}\end{array}$ & $\mathrm{v}$ & $\mathrm{v}$ & \\
\hline
\end{tabular}

Figura 2. Representação do Realismo Crítico com Auxilio da Imagem do Iceberg.

Nota. Fonte: Adaptação do autor com base em Ackroyd, S., \& Fleetwood, S. (Eds.). (2000). Realist perspectives on management and organizations. London: Routledge. 
Os princípios do RC podem ser resumidos nos seguintes pontos (Outhwaite, 1987, pp. 45-46): (a) a realidade é estratificada em três domínios: empírico, factual, e real. O domínio do empírico consiste em eventos que podem ser observados; o domínio do factual consiste em eventos observados ou não; o domínio do real consiste nas estruturas e processos que geram a realidade e que produzem eventos; (b) relações causais são tidas como tendências ou poderes de coisas que interagem com outras tendências, de forma que um evento observável pode ou não ser produzido, e pode ou não ser observado; (c) mecanismos explanatórios no domínio do real são postulados; ao pesquisador cabe tentar demonstrar sua existência; (d) os objetos transitivos e intransitivos da ciência são distintos. Objetos transitivos são os conceitos, teorias e modelos que são desenvolvidos para entender e explicar alguns aspectos da realidade. Objetos intransitivos são as entidades reais e suas relações que produzem o mundo.

Visto que o conhecimento é falível, como avaliar então as descobertas do pesquisador? RC defende o critério de plausibilidade, o qual se baseia no confronto de teorias e em julgamentos intersubjetivos. $\mathrm{O}$ argumento central é que sempre existe uma melhor descrição da realidade, que se aproxima da dimensão intransitiva do conhecimento ou ontológica da ciência (Bhaskar, 1998). Uma melhor descrição da realidade é alcançada quando: (a) os mecanismos e as estruturas postulados são capazes de explicar fenômenos de interesse; (b) temos boas razões para acreditar em sua existência; e (c) não podemos pensar em alternativas igualmente boas (Bhaskar, 1997, p. 58).

Além de reconhecer que descrições e explicações de atores sociais sobre a realidade não são neutras, o pesquisador deve adotar uma abordagem interdisciplinar para descobrir mecanismos, estruturas e redes causais que estão invisíveis para dada área do conhecimento. Como se ilustra a seguir, a literatura de redes, baseada em economia política internacional, nos ajuda tanto a produzir pesquisa relevante no âmbito de redes estratégicas, quanto a compreender o subdesenvolvimento da pesquisa em redes estratégicas.

\section{Uma Aplicação Simplificada da Abordagem Crítica}

A abordagem crítica, apresentada na seção anterior, pode ajudar-nos a compreender tanto as redes estratégicas quanto o processo de ascensão e queda do conhecimento acadêmico em redes estratégicas nos anos 1990, com foco especial nas influências do setor automotivo. Tais antecedentes ajudam a explicar a proposta reducionista sobre redes estratégicas publicada em 2000 pelo SMJ.

A influência do setor automotivo sobre o campo da administração é amplamente conhecida, ilustrada pelas disciplinas baseadas nos sistemas de linha de produção e na estrutura hierárquica de especialização de tarefas nas grandes montadoras nos EUA. O setor impulsionou o surgimento da administração científica nos EUA, o estabelecimento e difusão internacional do taylorismo e do fordismo, e ainda teve papel central na Segunda Guerra Mundial. O ditado 'o que é bom para a General Motors (GM) é bom para o país’ foi difundido internacionalmente pela área de estratégia e ajudou a universalizar, em diferentes países, os interesses específicos da GM e a "legitimar a busca de apoio de políticas públicas para seus propósitos específicos” (Shrivastava, 1986, p. 366), a despeito do poder da imagem da firma como entidade autônoma nos EUA.

O setor automotivo liderou, a partir do final dos anos 1980, a construção de redes que se espalharam internacionalmente e também patrocinou a produção e a difusão de conhecimento acadêmico correspondente (e.g., Lamming, 1993; Womack, Jones, \& Roos, 1990). O poder políticoeconômico e ideológico do setor automotivo em nível mundial (Böhm, Jones, Land, \& Paterson, 2006), e sua histórica influência sobre o meio acadêmico - em especial na área de estratégia nos EUA (Knights \& Morgan, 1991; Whittington, 2001) - são questões da parte submersa do iceberg que ajudam a explicar tanto o subdesenvolvimento da pesquisa em redes estratégicas quanto as redes estratégicas lideradas por grandes montadoras. 
A compreensão das redes estratégicas neste setor e a análise do processo de ascensão e queda da pesquisa neste âmbito exigem que o pesquisador transcenda o visível. Assim como deveria ter feito o comandante do Titanic, o pesquisador deve diferenciar "a superfície aparente e as estruturas profundas [da realidade]" (Marsden, 1993, p. 119) e trazer à tona coisas tidas como 'não empíricas' ou 'invisíveis'. Pesquisas no âmbito de redes baseadas na literatura de economia política internacional são cruciais para esse propósito.

Podemos destacar os conceitos de "empresas como redes sociopolíticas”, propostos por Yeung (2005, p. 315); “cadeias globais”, propostas por (Gereffi, 1994, p. 97; Gereffi et al., 2005, p. 79); "redes genéricas", propostas por Dicken et al.(2001, p. 91), e ainda o framework de "redes globais de produção”, propostas por Henderson et al.(2002, p. 497). A principal virtude dessa literatura de redes, baseada em economia política internacional, cujo detalhamento transcende o escopo deste artigo, é abordar questões relegadas pelo âmbito de redes estratégicas, tais como: (a) o papel político das redes (assimétricas) lideradas por grandes corporações de economias avançadas junto a governos nacionais e subnacionais em economias emergentes e menos desenvolvidas; (b) o poder político dessas redes para o desempenho de setores e sistemas socioeconômicos específicos e também para a construção ou desmantelamento de mercados ou setores em países e regiões menos desenvolvidos; e (c) a importância das redes compostas por corporações e governos de economias emergentes e menos desenvolvidas.

Essa literatura reconhece o poder econômico-político do setor automotivo - especialmente dos EUA e Reino Unido - e as estruturas e mecanismos sócio-históricos correspondentes a diferentes países e à academia. No Reino Unido, por exemplo, a construção das redes estratégicas no setor automotivo - desafiando os fundamentos legais do capitalismo liberal de mercado e a imagem da firma como entidade autônoma - e a ascensão da literatura de redes foram tornadas possíveis pelas reformas político-econômicas, que foram iniciadas no governo neoliberal de Margareth Thatcher. Nos EUA, os processos correspondentes e os resultados controversos, observados posteriormente em diversos países (até mesmo nos EUA), foram iniciados no governo neoliberal de Ronald Reagan.

No Reino Unido, por exemplo, três conjuntos de mecanismos, estruturas e redes causais (de acordo com o esquema do RC), ajudam a explicar o processo de ascensão e queda da literatura de redes: (a) a desnacionalização da indústria automotiva local demandou a construção de uma nova rede de corporações livres das influências do antigo governo, que viria a se beneficiar, em termos políticos e econômicos, do regime neoliberal de mercado não apenas no Reino Unido, mas também no exterior (Ruigrok \& Tulder, 1995); (b) o estabelecimento do neoliberalismo demandava o enfraquecimento das políticas industriais locais e o desmantelamento das redes locais, envolvendo grandes empresas, sociedade, e governo (Best, 1990); e (c) a entrada de montadoras estrangeiras reforçou as políticas de reestruturação do governo, em especial a captura política de cidades por grandes empresas e a formação de redes políticas que se dedicaram a desmantelar as estruturas de poder político-sindical em regiões importantes do Reino Unido (Oliver \& Wilkinson, 1992).

No Brasil, o processo de formação de cadeias globais e de redes globais assimétricas (Dicken, 1998) - liderado pelo centro geopolítico do setor automotivo - contou com a imposição de reformas neoliberais no país e em outros países e regiões. A implantação das redes no setor automotivo no país foi precedida pela desregulamentação iniciada no governo neoliberal de Fernando Collor. Durante o governo de Fernando Henrique Cardoso, houve a reestruturação do setor por meio de incentivos governamentais à entrada de grandes volumes de investimentos diretos estrangeiros, feitos por grandes montadoras. O 'Novo Regime Automotivo' refletiu no Brasil em grande parte o processo neoliberal de enfraquecimento do Estado em relação às grandes corporações, de acordo com os preceitos do Consenso de Washington (Broad, 2004). As transformações resultantes beneficiaram substancialmente os estrategistas das grandes corporações e governos de economias avançadas e, mais modestamente, alguns estrategistas de empresas e governos locais, em detrimento da maioria da sociedade (Arbix et al., 2002; Bedê, 1997; Laplane \& Sarti, 2002; Rodrígues-Pose \& Arbix, 2001).

As aquisições de importantes empresas fornecedoras nacionais por grupos estrangeiros, o enxugamento e o achatamento dos quadros de funcionários do setor automotivo, e o esvaziamento do 
sindicato na região do $\mathrm{ABCD}$ paulista resultaram em uma rápida reestruturação geopolítica ou geoeconômica do setor no Brasil. A maior parte da literatura de estratégia produzida no país ignorou tais questões de poder e política e ajudou a impulsionar esse processo de reforma. A literatura de redes baseada em economia política mostra que o setor no Brasil é majoritariamente composto, atualmente, por redes assimétricas internacionais, envolvendo grandes montadoras, gerentes de redes, e governos de municípios sem grande tradição sindical (Betim-MG, São José dos Pinhais-PR, Juiz de Fora-MG, Porto Alegre-RS, Resende-RJ, Salvador-BA), que competiram com outros municípios de forma predatória para atender às demandas das montadoras (ver Arbix \& Zilbovicius, 1997).

Após a implantação dessas redes assimétricas e a emergência de críticas severas ao capitalismo neoliberal, a literatura de estratégia em redes estratégicas arrefeceu no Reino Unido e foi retomada recentemente nos EUA em perspectiva reducionista - ilustrada pelo número do SMJ publicado em 2000 - que vem sendo usada para a produção de conhecimento neste âmbito que seja relevante para economias emergentes.

\section{Considerações Finais}

Este artigo teve o principal objetivo de mostrar que pesquisadores no Brasil devem desafiar a literatura dominante de estratégia e reconhecer questões de poder e política, em âmbito nacional e internacional, que afetam tanto as redes estratégicas quanto o conhecimento acadêmico, para produzirem conhecimento relevante para estrategistas de organizações privadas e do governo e para a sociedade. Com base no reconhecimento da literatura de áreas como geografia, sociologia global e relações internacionais, e mais especificamente da literatura de redes baseada em economia política internacional, este artigo mostrou que os recentes investimentos feitos por pesquisadores e instituições anglo-americanas na construção de conhecimento relevante para economias emergentes, no âmbito das redes estratégicas e na área de estratégia como um todo, devem ser tratados como foco adicional de resistência e engajamento crítico por pesquisadores de economias emergentes.

Ao manter invisíveis importantes questões de política e poder, a literatura dominante de estratégia enfrenta dois problemas invisíveis que dificilmente serão resolvidos pelo mundo angloamericano. O principal problema é que ao mesmo tempo que estrategistas do mundo anglo-americano demandam a maior vinculação da área de estratégia a suas práticas e interesses para superar crises de relevância, pesquisadores da área não problematizam o interesse de estrategistas de grandes corporações pela omissão de questões de poder e política. O outro problema é que tanto estrategistas quanto acadêmicos não problematizam a hegemonia dos EUA no sistema internacional no contexto pós-Guerra Fria nem a hegemonia anglo-americana no campo da administração. Esse quadro justifica a construção de uma perspectiva crítica, em economias emergentes, para o desenvolvimento de pesquisa em redes estratégicas que desafiem e dialoguem criticamente com a literatura dominante. Resistência à literatura dominante, por meio de crítica distanciada, não é mais suficiente, tendo em vista o papel das economias emergentes no contexto internacional. O diálogo crítico com a literatura dominante é necessário e deve ser apoiado por uma estratégia de internacionalização da pesquisa em estratégia de economias emergentes, em direção ao mundo anglo-americano e a países que seguem outros tipos de capitalismo. Esta orientação é importante para o desenvolvimento da área de estratégia, a partir de economias emergentes, em contexto de pós-neoliberalismo oficialmente inaugurado pela crise financeira em 2008. Com base na perspectiva crítica desenvolvida neste artigo, pesquisadores do Brasil devem investigar redes estratégicas em outros países e regiões, e em especial no mundo angloamericano.

Neste sentido, diferentemente da trajetória de crescente especialização da área e de rejeição à crítica nos EUA, a aproximação histórica entre a área de EO e estratégia no Brasil é um ativo a ser explorado. Essa proximidade, em especial devido às críticas de pesquisadores de EO ao domínio anglo-americano e a resistência de autores vinculados a EO à literatura dominante de estratégia, torna mais plausível a realização de desenvolvimentos interdisciplinares com áreas como geografia, 
sociologia global, e relações internacionais e, mais especificamente, com a literatura de redes baseada em economia política internacional.

O reconhecimento da parte submersa/invisível do iceberg exige que pesquisadores desafiem a imagem, construída nos EUA e exportada para o mundo, de que o estrategista da grande corporação é o principal estrategista de um país (Chandler, 1977; Pettigrew et al., 2002) ${ }^{(1)}$. Acadêmicos no mundo anglo-americano divergem sobre o que é estratégia, mas concordam com o privilégio concedido a esses tipo de estrategista. Isso tem sido importante para sustentar um tipo de capitalismo e a legitimar as escolas de negócios e as grandes corporações nos EUA e no exterior e também para reforçar a expansão internacional das instituições e conhecimentos made in US. Ademais, também tem sido importante para inibir a construção de conhecimento relevante em outros contextos, tais como as economias emergentes. Este artigo argumenta que a pesquisa no âmbito de redes estratégicas pode construir o necessário entendimento de que estratégia não se restringe a um conjunto de ações realizadas ou percebidas por gerentes/estrategistas de grandes empresas.

Pesquisa em redes estratégicas que seja relevante para estrategistas de empresas privadas e de organizações governamentais é de grande importância para as economias emergentes, como o Brasil, devido a dois fatores adicionais: a expansão das redes assimétricas lideradas por economias desenvolvidas em direção às economias emergentes, e a importância da defesa de capitalismos de economias emergentes, em contexto internacional marcado por excessos do neoliberalismo e pela disputa assimétrica entre tipos de capitalismo.

A despeito das limitações enfrentadas por quem busca reconhecer as partes invisíveis da realidade, o autor deste artigo sugere que o interesse de estrategistas de manter invisíveis questões de poder e política não se restringe ao mundo anglo-americano. Correspondentemente não é implausível que estrategistas de empresas privadas e do governo em economias emergentes prefiram a pesquisa em redes estratégicas fomentada por pesquisadores e instituições anglo-americanas. Por essa razão pesquisa em redes estratégicas deve buscar a construção de conhecimento relevante não apenas para estrategistas de empresas privadas e organizações governamentais, mas para a sociedade.

\section{Nota}

\footnotetext{
${ }^{1}$ A área de estratégia se afastou dessas questões desde a publicação do influente trabalho de Alfred Chandler. Ao construir uma teoria para o crescimento da grande empresa, Chandler, A. (1962). Strategy and structure: chapters in the history of the American industrial enterprise. Cambridge, MA: MIT Press, ajudou a suprimir o caráter político da estratégia das grandes corporações e as interfaces de governo e empresa nos EUA. Ele ajudou a estabelecer o pressuposto de que gerentes - por meio da imagem da "mão visível”- governam a economia nacional (Chandler, 1977, p. 286). O trabalho de Chandler ajudou a tornar invisível as elites (Mills, C. (1959). The power elite. New York: Oxford University) e os correspondentes mecanismos e estruturas no âmbito de pesquisa e ensino em administração.
}

Artigo recebido em 28.12.2009. Aprovado em 02.08.2010.

\section{Referências}

Ackroyd, S., \& Fleetwood, S. (Eds.). (2000). Realist perspectives on management and organizations. London: Routledge.

Albert, M. (1992). The Rhine model of capitalism: an investigation. European Business Journal, 4(3), $8-22$.

Altvater, E. (2009). Postneoliberalism or postcapitalism? The failure of neoliberalism in the financial market crisis. Development Dialogue, (51), 73-87. 
Alvesson, M., \& Willmott, H. (2003). Studying management critically. London: SAGE.

Arbix, G., Comin, A., Zilbovicius, M., \& Abramovay, R. (Orgs.). (2002). Brasil, México, África do Sul, Índia e China: diálogo entre os que chegaram depois. São Paulo: UNESP, USP.

Arbix, G., \& Zilbovicius, M. (Eds.). (1997). De JK a FHC. A reinvenção dos carros. São Paulo: Scritta.

Axelsson, B., \& Easton, G. (Eds.). (1992). Industrial networks: a new view of reality. London: Routledge.

Barney, J. (1991). Firm resources and sustained competitive advantage. Journal of Management, 17(1), 99-120.

Bedê, M. (1997). A política automotiva nos anos 90. In G. Arbix \& M. Zilbovicius (Orgs.), De JK a FHC. A reinvenção dos carros (pp. 357-387). São Paulo: Scritta.

Benko, G., \& Strohmayer, U. (Eds.). (1997). Space and social theory. Oxford: Blackwell.

Benson, K. (1994). The interorganizational network as a political economy. In J. Scott (Ed.), Power: critical concepts (Vol 3). London: Routledge.

Bertero, C., Vasconcelos, F., \& Binder, M. (2003). Estratégia empresarial: a produção científica brasileira entre 1991 e 2002. Revista de Administração de Empresas, 43(4), 48-62.

Best, M. (1990). The new competition - institutions of industrial restructuring. Cambridge: Polity Press.

Bettis, R., \& Prahalad, C. (1995). The dominant logic: retrospective and extension. Strategic Management Journal, 16(1), 5-14.

Bhaskar, R. (1989). The possibility of naturalism: a philosophical critique of the contemporary human sciences (2nd ed.). Hemel Hampstead: Wheatcheaf.

Bhaskar, R. (1997). A realist theory of science (2nd ed.). London: Verso.

Bhaskar, R. (1998). General introduction. In M. Archer, R. Bhaskar, A. Collier, T. Lawson, \& A. Norrie (Eds.), Critical realism: essential readings (pp. 3-15). London: Routledge.

Bignetti, L. (2008). Comentários - Uma apreciação sobre o desenvolvimento dos estudos em estratégia no Brasil sob a inspiração de Hafsi e Martinet. Revista de Administração Contemporânea, 12(4), 1165-1171.

Blaikie, N. (1993). Approaches to social enquiry. London: Polity.

Böhm, S., Jones, C., Land, C., \& Paterson, M. (2006). Introduction: impossibilities of automobility. Sociological Review, 54(Supl. s1), 1-16.

Boisot, M., \& Child, J. (1996). From fiefs to clans and network capitalism: explaining China's emerging economic order. Administrative Science Quarterly, 41(4), 600-628.

Brahm, R. (1995). National targeting policies, high-technology industries, and excessive competition. Strategic Management Journal, 16(S1), 71-91.

Broad, R. (2004). The Washington consensus meets the global backlash: shifting debates and policies. Globalizations, 1(2), 129-154.

Carter, C., Clegg, S., \& Kornberger, M. (2008). Strategy as practice? Strategic Organization, 6(1), 8399. 
Chandler, A. (1977). The visible hand: the managerial revolution in American business. Cambridge, MA: Harvard University.

Chandler, A. D. (1984). The emergence of managerial capitalism. Business History Review, 58(4), 473-503.

Clark, T. (2004). Strategy viewed from a management fashion perspective. European Management Journal, 1(1), 105-111.

Clegg, S., Carter, C., \& Kornberger, M. (2004). A "máquina estratégica”: fundamentos epistemológicos e desenvolvimentos em curso. Revista de Administração de Empresas, 44(4), 21-31.

Clegg, S., \& Ross-Smith, A. (2003). Revising the boundaries: management education and learning in a postpositivist world. Academy of Management Learning and Education, 2(1), 85-98.

Combe, I. (1999). Multiple strategy paradigms: an integrational framework. Journal of Marketing Management, 15(5), 341-359.

Courpasson, D., Arellano-Gault, D., Brown, A., \& Lounsburry, M. (2008). Organization studies on the look-out: being read, being listened to. Organization Studies, 29(11), 1383-1390.

Cummings, S., \& Wilson, D. (Eds.). (2003). Images of strategy. London: Blackwell.

Dicken, P. (1998). Global shift: transforming the world economy. London: Paul Chapman.

Dicken, P., Kelly, P., Olds, K., \& Yeung, H. (2001). Chains and networks, territories and scales: towards a relational framework for analyzing the global economy. Global Networks, 1(2), 89112.

Fleetwood, S., \& Ackroyd, S. (Eds.). (2004). Critical realist applications in organisation and management studies. London: Routledge.

Gaddis, P. (1997). Strategy under attack. Long Range Planning, 30(1), 38-45.

Gereffi, G. (1994). The organisation of buyer-driven global commodity chains: how US retailers shape overseas production networks. In G. Gereffi \& M. Korzeniewicz (Eds.), Commodity chains and global capitalism (pp. 95-122). Westport: Praeger.

Gereffi, G., Humphrey, J., \& Sturgeon, T. (2005). The governance of global value chains. Review of International Political Economy, 12(1) 78-104.

Ghemawat, P. (2006). Estratégias regionais para a liderança global. Harvard Business Review, 84(8), 98-108.

Ghoshal, S. (2005). Bad management theories are destroying good management practices. Academy of Management Learning and Education, 4(1), 75-91.

Godfrey, P., \& Hill, C. (1995). The problem of unobservables in strategic management research. Strategic Management Journal, 16(7), 519-533.

Grandy, G., \& Mills, A. (2004). Strategy as simulacra? A radical reflexive look at the discipline and practice of strategy. Journal of Management Studies, 41(7), 1153-1170.

Gulati, R., Nohria, N., \& Zaheer, A. (2000b). Guest editors' introduction to the special issue: strategic networks. Strategic Management Journal, 21(3), 199-201.

Gulati, R., Nohria, N., \& Zaheer, A. (2000a). Strategic networks. Strategic Management Journal, 21(3), 203-215. 
Haley, G., \& Tan, C. (1999). East vs. west: strategic marketing management meets the Asian networks. Journal of Business \& Industrial Marketing, 14(2), 91-101.

Hambrick, D. (2004). The disintegration of strategic management: it's time to consolidate our gains. Strategic Organization, 2(1), 91-98.

Henderson, J., Dicken, P., Hess, M., Coe, N., \& Yeung, H. W.-C. (2002). Global production networks and the analysis of economic development. Review of International Political Economy, 9(3), 436-464.

Harvey, D. (2007) A brief history of neoliberalism. Oxford: Oxford University.

Hoskisson, R., Eden, L., Lau, C., \& Wright, M. (2000). Strategy in emerging economies. Academy of Management Journal, 43(3), 249-267.

Humphrey, J. (2003). Globalization and supply chain networks: the auto industry in Brazil and India. Global Networks, 3(2), 121-141.

Ibarra-Colado, E. (2006). Organization studies and epistemic coloniality in Latin America: thinking otherness from the margins. Organization, 13(4), 489-508.

Ikenberry, G. (2004). Illusions of empire: defining the new American order. Foreign Affairs, 83(2), 144-154.

Kaplinski, R. (2004). Spreading the gains from globalization. Problems of Economic Transition, 47(2), 74-115.

Kay, J. (2004). The truth about markets. London: Penguin.

Khurana, R., \& Marquis, C. (2006). Diagnosing and dissolving our "translation gap". Journal of Management Inquiry, 15(4), 406-409.

Kils, U. (2006, julho). File: Iceberg.jpg. Recuperado de http://commons.wikimedia.org/wiki/Image:Iceberg.jpg

Knights, D., \& Morgan, G. (1991). Strategic discourse and subjectivity: towards a critical analysis of corporate strategy in organizations. Organization Studies, 12(2), 251-273.

Koniordos, S. (Ed.). (2005). Networks, trust, and social capital. London: Ashgate.

Kwan, K., \& Tsang, W. (2001). Realism and constructivism in strategy research: a critical realist response to Mir and Watson. Strategic Management Journal, 22(12), 1163-1168.

Lamming, R. (1993). Beyond partnership: strategies for innovation and lean supply. London: Prentice Hall.

Laplane, M., \& Sarti, F. (2002). Costs and paradoxes of market creation: evidence and argument from Brazil. Competition \& Change, 6(1), 127-141.

Lecraw, D. (1984). Bargaining power, ownership and profitability of transnational corporations in developing countries. Journal of International Business Studies, 15(1), 27-43.

Levy, D., Alvesson, M., \& Willmott, H. (2003). Critical approaches to strategic management. In M. Alvesson \& H. Willmott (Eds.), Studying management critically (Chap. 5, pp. 92-110). London: Sage.

Lorenzoni, G., \& Baden-Fuller, C. (1995). Creating a strategic center to manage a web of partners. California Management Review, 37(3), 146-163. 
Lowendahl, B., \& Revang, O. (1998). Challenges to existing strategy theory in a postindustrial society. Strategic Management Journal, 19(8), 755-773.

Machado-da-Silva, C. (2004). Estratégia e organizações: conversação necessária. In S. Clegg, C. Hardy, \& W. Nord (Orgs.), Handbook de estudos organizacionais (pp. 69-76). São Paulo: Atlas.

Marsden, R. (1993). The politics of organizational analysis. Organization Studies, 14(1), 93-124.

Mattsson, L.-G., \& Johanson, J. (2006). Discovering market networks. European Journal of Marketing, 40(3-4), 259-274.

Mintzberg, H., \& Quinn, J. (2001). O processo da estratégia. Porto Alegre: Bookman.

Mir, R., \& Watson, A. (2000). Strategic management and the philosophy of science: the case for a constructivist methodology. Strategic Management Journal, 21(9), 941-953.

Murtha, T., \& Lenway, S. (1994). Country capabilities and the strategic state: how national political institutions affect multinational corporations' strategies. Strategic Management Journal, 15(S2), 113-129.

Ohmae, K. (1988). Getting back to strategy. Harvard Business Review, 66(6), 149-156.

Oliver, N., \& Wilkinson, B. (1992). The japanization of British industry. Oxford: Blackwell.

Outhwaite, W. (1983). Toward a realist perspective. In G. Morgan (Ed.), Beyond Method: Strategies for Social Research (pp. 321-330). Beverly Hills, CA: Sage.

Outhwaite, W. (1987). New philosophies of social science: realism, hermeneutics and critical theory. London: Macmillan.

Peng, M., \& Pleggenkuhle-Miles, E. (2009). Current debates in global strategy. International Journal of Management Reviews, 11(1), 51-68.

Peng, M., Wang, D., \& Jiang, Y. (2008). An institution-based view of international business strategy: a focus on emerging economies. Journal of International Business Studies, 39(5), 920-936.

Pettigrew, A., Thomas, H., \& Whittington, R. (2002). Strategic management: the strengths and limitations of a field. In A. Pettigrew, H. Thomas, \& R. Whittington (Eds.), Handbook of strategy and management (pp. 165-182). London: Sage.

Phelan, S., Ferreira, M., \& Salvador, R. (2002). The twenty years of the Strategic Management Journal. Strategic Management Journal, 23(12), 1161-1168.

Ramamurti, R. (2001). The obsolescing 'bargaining model'? MNC-Host developing country relations revisited. Journal of International Business Studies, 32(1), 23-29.

Ricart, J., Enright, M., Ghemawat, P., Hart, S., \& Khanna, T. (2004). New frontiers in international strategy. Journal of International Business Studies, 35(3), 175-200.

Rodrígues-Pose, A., \& Arbix, G. (2001). Strategies of waste: bidding wars in the Brazilian automobile sector. International Journal of Urban and Regional Research, 25(1), 134-154.

Ruigrok, W., \& Tulder, R. van (1995). The logic of international restructuring. London: Routledge.

Rumelt, R., Schendel, D., \& Teece, D. (1991). Strategic management and economics. Strategic Management Journal, 12(S2), 5-29.

Saraiva, E., \& Carrieri, A. (2009). Citações e não citações na produção acadêmica de estratégia no Brasil: uma reflexão crítica. Revista de Administração da USP, 44(2), 158-166. 
Sayer, A. (1992). Method in social science: a realist approach (2nd ed.). London: Routledge.

Schelhase, M. (2008). Globalization, regionalization and business. Basingtoke: Palgrave Macmillan.

Schendel, D., Ansoff, I., \& Channon, D. (1980). Statement of editorial policy. Strategic Management Journal, 1(1), 1-5.

Seth, M., \& Thomas, H. (1994). Theories of the firm: implications for strategy research. Journal of Management Studies, 31(2), 165-190.

Shrivastava, P. (1986). Is strategic management ideological? Journal of Management, 12(3), 363-377.

Sklair, L. (2002). Globalization, capitalism and its alternatives. Oxford: Oxford University.

Snow, C., \& Thomas, J. (1994). Field research methods in strategic management: contributions to theory building and testing. Journal of Management Studies, 31(4), 457-480.

Steger, M. (2003). Globalization: a very short introduction. Oxford: Oxford University.

Teece, D., Pisano, G., \& Shuen, A. (1997). Dynamic capabilities and strategic management. Strategic Management Journal, 18(7), 509-533.

Tsoukas, H. (1994a). Refining common sense: types of knowledge in management studies. Journal of Management Studies, 31(6), 761-780.

Tsoukas, H. (1994b). What is management? An outline of a metatheory. British Journal of Management, 5(4), 289-301.

Vergara, S. (2001). A hegemonia americana em estudos organizacionais. Revista de Administração Pública, 35(2), 63-77.

Walsh, J., Meyer, A., \& Schoonhoven, C. (2006). A future for organization theory: living in and living with changing organizations. Organization Science, 17(5), 657-671.

Welch, C., \& Wilkinson, I. (2004). The political embeddedness of international business networks. International Marketing Review, 21(2), 216-231.

Westwood, R., \& Jack, G. (2008). The US commercial-military-political complex and the emergence of international business and management studies. Critical Perspectives on International Business, 4(4), 367-388.

Whittington, R. (2001). O que é estratégia. São Paulo: Pioneira.

Whittington, R. (2004). Estratégia após o modernismo: recuperando a prática. Revista de Administração de Empresas, 44(4), 44-53.

Whittington, R., Jarzabkowski, P., Mayer, M., Mounoud, E., Nahapiet, J., \& Rouleau, L. (2003). Taking strategy seriously. Journal of Management Inquiry, 12(4), 396-409.

Wilson, D. (1992). A strategy of change. London: Thomson.

Womack, J., Jones, D., \& Roos, D. (1990). The machine that changed the world. New York: Rawson Associates.

Yeung, H. (2005). The firm as social networks: an organizational perspective. Growth \& Change, 36(3), 307-328. 